\title{
Narrative and Autobiographical Approaches to Leaving Religion
}

\author{
Peter G. Stromberg \\ 1 Introducing Narrative and Autobiographical Approaches to \\ Leaving Religion
}

People leave religious institutions or change their religious beliefs for many different reasons. A person might change their religious affiliation because a political transformation has rendered that affiliation dangerous or economically undesirable; there may be some form of coercion involved. For example, the colonisation process with its attendant Christian missionisation entailed a massive replacement, on several continents, of indigenous religions with some version of Christianity. Did the people who abandoned indigenous religions deconvert? Of course, this is but one of many possible scenarios of religious change. A person might gradually abandon the faith in which they were raised, or might encounter a religious tradition that for one reason or another seems extraordinarily compelling, and for that reason leave her old faith for a new one.

Whether all of these phenomena should be considered instances of deconversion is by no means resolved. Furthermore, the similarity between such instances of leaving religion may be only superficial, and thus a single theoretical framework - a single general explanation for all of these cases - may not be possible. For these reasons, writing coherently about leaving religion requires one to specify which sort of leaving is being explained. In most of the literature on leaving religion, the phenomenon is studied in the context of the contested ideological situations in contemporary societies (although important exceptions are found in Part 1 and 2 of this book). As Gooren (2011) notes, in practice the study of deconversion was shaped by its origins in the context of sociological study of new religious movements that arose in the early 1970s. Since that time the purview of the topic has expanded considerably, but it is fair to note that to some extent the concerns of these early studies established the paradigm in this literature.

Above all-and Gooren's (2010) thorough review and synthesis of the literature on conversion and disaffiliation makes this clear-across several 
disciplines, research on the topic has been oriented around questions about the "religious marketplace." This terminology alerts us to the fact that most of this work has been carried out in situations not only of religious pluralism, but in contexts in which religious groups are in some sense in competition for members. It is the study of such situations that constitutes the prototypical case of leaving religion in the literature, and this fact to some extent determines the questions that will be asked about the phenomenon. In the current chapter, I will stay within the boundaries established by these broad trends in this area of study. And within these boundaries, I am concerned to review, evaluate, and perhaps help to develop approaches based on the study of autobiography and narrative. As such, this chapter is primarily methodological. Collection of narratives is a research method, and the question is, what are the advantages, disadvantages, and implications of this method?

Probably the dominant strain of the research literature on narrative and deconversion has its origins in sociology and social psychology of religion, and adopts a generally positivist approach. In such an approach, language is assumed to transparently reflect underlying forces that are the true target of analysis. As is the case in the natural sciences, the analyst assumes that empirical phenomena (such as narratives) can be explained by discovering underlying stable principles that produce those phenomena. In this approach, the analyst does not focus on language or narrative in itself. Rather, narratives are used to discover and document underlying social factors that are in themselves considered causal.

An example is Janet Jacobs (1987) study entitled "Deconversion from Religious Movements: An Analysis of Charismatic Bonding and Spiritual Commitment." Based on 40 intensive interviews with previous members of several movements she characterizes as "authoritarian," Jacobs reports two significant findings. First, her subjects report that their deconversions were-in her terms - "evolutionary," that is, gradual rather than sudden. ${ }^{1}$ Second, the process of deconversion was driven by disenchantment with the leader of the group.

The year after Jacobs' study, an edited collection entitled Falling from the Faith: Causes and Consequences of Religious Apostasy (Bromley 1988) appeared.

1 The term "evolutionary" here seems unnecessarily confusing, in that it is usually used to denote a process of development. 
Although not all of the studies contain narrative material, a number of them do, and they utilize narrative material in a manner similar to Jacobs. Perhaps the most interesting of these studies, from the perspective of developing narrative analysis, is Susan Rothbaum's chapter entitled "Between Two Worlds: Issues of Separation and Identity after Leaving a Religious Community." Rothbaum (1988) offers an insightful analysis of narrative materials to document the emergence, in deconversion stories, of a sense of personal identity that contrasts to the more collective identity fostered by participation in the religious group.

Another, more recent example of this approach is Wright et al. (2011), "Explaining Deconversion from Christianity: A study of Online Narratives." Working within a rational choice paradigm, the authors seek to understand deconversion by studying written autobiographical narratives posted online. The narratives are analysed using a coding system that classifies subjects' explanations into a few general categories that occurred repeatedly in the corpus of fifty narratives. The authors find three explanations that occur frequently, and one more that occurs less often. The three common explanations are: "intellectual and theological concerns, God's shortcomings, and interactions with Christians." (Wright et al. 2011: 6). The final reason is interaction with nonChristians. By intellectual and theological concerns, the authors mean to refer to statements to the effect that the tenets of Christianity often contradict basic principles of science or provide a weak explanation for such problems as human suffering. "God's shortcomings" refers most frequently to subjects' experiences of praying for help with personal problems and failing to find it. "Interactions with Christians" concerns matters such as hypocrisy among Christians, their failing to live up to their professed moral standards. Finally, interaction with non-Christians covers stories about being convinced to abandon Christianity by the arguments of non-believers.

Perhaps the most ambitious and thorough studies of deconversion narratives within the positivist approach have been carried out by Heinz Streib and his colleagues. Like Jacobs, they find that the most common trajectory in the deconversion story is that of a gradual disaffiliation from a faith tradition (Streib et al. 2009: 95). However, they expand on this finding. Their analysis of deconversion stories eventually leads them to identify four general types of deconversion stories or trajectories. The first is "Pursuit of Autonomy," by which they mean separation from a religious tradition in which the subject was raised and which the subject adopted in a generally unquestioning way. The second is "Debarred from Paradise," referring to leaving a religious tradition to which the subject had previously made a strong emotional commitment. In other words, the central contrast between the first and second narrative themes has 
to do with whether one is leaving a religion that one has accepted as a matter of course or one that one has embraced through a strong emotional commitment, either through growing up in the religion or converting to it. The third trajectory, "Finding a New Frame of Reference," embraces stories of loss of faith followed by conversion to a tradition that the subject, for one reason or another, finds to be more engaging. (The narratives in this category could equally well be labelled conversion stories.) Finally, the authors suggest a category of "Life-Long Quests-Late Revisions." These stories are in essence extended versions of the ones found in the previous category; they entail what is often called a "seeker" orientation, which may be realised as commitment to and subsequent deconversion from multiple religious traditions.

I should note that although primarily positivist in its research method, the analysis here introduces a value orientation through its reliance on James W. Fowler's (1991) scheme of religious development. ${ }^{2}$ That is, the authors integrate the question of whether deconversion entails faith development into their research design (Streib et al. 2009: 100-101). Their general, and heavily qualified, conclusion about religious development is that more often than not deconversion results in a psychological situation that is higher in openness to experience and lower in right-wing authoritarianism, religious fundamentalism and absolutism (Streib et al. 2009: 232).

The other central (although somewhat less prominent) theoretical stance underlying work on narrative and the deconversion can be labelled "discursive" and is distinguished from the positivist approach in the first place by a different conception of the role of language. Rather than seeing language as a medium that transparently reflects aspects of the world, discourse analysts assume that language plays a significant part in determining how humans perceive and understand the world. Hence studies undertaken from this theoretical stance unfold not as quests to discover what social, cultural, and psychological factors cause deconversion but rather to illuminate how language itself (and by extension, narrative) constructs the deconversion.

Those who adopt this approach do not necessarily give up on finding underlying social or psychological factors that contribute to deconversion, however they hold that such factors can only be revealed through careful analysis of the language of the deconversion narrative. Furthermore, the emphasis on how the believer's language constructs the deconversion leads naturally to an

2 Considering some forms of belief to be "higher" than others in a developmental sense is not a judgment that I personally consider to be sustainable. However, I recognize that some disciplines approach such questions differently than anthropologists typically do. This dispute is not central to the present endeavor, and I will not pursue it here. 
emphasis on the deconversion narrative as a means whereby believers construct meaning in their lives. In sum, the discursive approach is typically oriented around how a believer uses language and narrative to make sense of his or her situation, and it may also go beyond this to seek regularities in the social and psychological factors that underpin the deconversion.

An example of the latter is Gooren's (2010) "conversion career" approach, which is built on the conviction that at bottom deconversion is about subjects trying to find coherence and meaning. (I would agree with Gooren and other authors such as Barbour (1994) and Larsson (2017) that in this sense deconversion and conversion are the same). Since none of us has the option of adopting a neutral point of view, every position in the world entails a set of assumptions about the nature of reality. "All human beings need a philosophy, whether atheism or a religion, to give meaning to their lives" (Gooren 2010: 131). From this perspective, what is at stake in the study of deconversion (or conversion) are the processes whereby persons manage to change the context of meaning in which they are embedded. How is this accomplished, and what are its social and psychic consequences?

In attempting to clarify this process, Gooren turns to the study of believers' narratives, illustrating that narrative analysis is often the favoured means for analysing questions about meaning. It is a significant clue that many conversion stories turn around moments of anguish, experiences when the believer faces the despair born of meaninglessness.

It will be useful to look at one of Gooren's narratives in a bit more detail, and I will choose one that I know well, in that it is taken from my own work (Stromberg 1993). Gooren introduces the case of evangelical Christian George by citing a passage in which George talks about his father, a committed Christian who hoped George would follow in his religious footsteps. However, George strayed from the path, and eventually abandoned his wife and young children. On a subsequent visit with his family, George was overcome with regret when he recognized that he had in effect abandoned his children, and shortly thereafter he returned to his father's faith. Gooren (2010: 87) cites this as an example of "the importance of social factors in the conversion process" since the conversion is precipitated by George's profound feelings of pain upon realising his separation from his children. However, Gooren could also have noted that in converting, George was simultaneously embracing his father's religion and devotion to his family. It is this alignment with his own personal history that strongly contributes to George's conviction that his conversion restored a sense of meaning in his life.

Gooren, then, combines the quest to find underlying social and psychological factors that account for conversion and deconversion with a discursive 
approach that seeks to illuminate how believers use narratives to fashion a context of meaning. Barbour (1994) illustrates another approach that is more closely attentive to the language of the narrative in order to illuminate processes of meaning-creation. One might imagine that the conventions whereby the deconversion narrative takes shape are frills that can be dispensed with in studying the deconversion itself. But Barbour would ask (as I would), where is this deconversion itself, where in the universe does it reside? If the answer is that it is an event or series of events that occurred in the past and caused certain changes in the narrator, then our access to the deconversion is forever blocked. In fact, we have access to the deconversion only through what the subject reports, which is for the most part the deconversion narrative. In this sense the conventions used in the deconversion narrative not only recount but actually constitute the deconversion (Stromberg 1993, Avance 2013).

The deconversion is also, as Barbour points out in discussing John Stuart Mill (1806-1873), a transformation of self that may affect the entire person, including their emotions and the moral environment in which he or she dwells (Barbour 1994: 46). Mill's narrative account of his deconversion centers on an abandonment of his father's view of an approach to life-symbolic of "the most disagreeable aspects of the Calvinist God" (1994: 47) — for the more humanist views of his wife, Harriet Taylor. The deconversion is at once a change in belief, a coming of age, and the emergence of a literary and philosophical voice. Such a case study makes that point that deconversion may be intertwined with a wide range of issues that impinge upon personal experience and history. Studying this process allows us to understand conversion and deconversion as they illustrate the broader processes whereby human beings integrate themselves with moral communities.

The two theoretical orientations I have identified correspond rather neatly to two different methods. While both orientations begin with collecting narratives, how the narratives are collected, presented, and analysed tends to differ between the two orientations. From the positivist perspective, the narrative is of interest not in itself but rather to the extent it provides evidence for underlying causal factors. For example, Streib and his colleagues adopt a mixed methods approach that combines questionnaire research with 99 open ended narrative interviews with persons who deconverted (Streib et al. 2009: 93). However, in their analysis narrative is used almost exclusively as an extended form of questionnaire research. This is evident in their dependence on the 
practice-widespread within the positivist orientation - of substituting for the narrative itself a series of codes that attempt to capture common themes in the corpus of interviews. I will comment on the implications of this practice below; for now it is sufficient to note that this approach is clearly distinct from that taken in discourse analysis.

Although there are a wide variety of methods brought to bear by discourse analysts, they share a close attention to the role of language and speech in the deconversion narrative itself. Here the focus is on the various conventions of narrative itself: metaphor, plot devices, figuration, and so on. A common analytic device (see for example Enstedt and Larsson 2013) is to seek to understand the persistence of certain themes and figures in the narratives that take shape through a historical tradition. Furthermore, as Barbour repeatedly points out, such narratives then become the patterns for subsequent ones. That is, the narrative conventions whereby a person constructs their deconversion serve as a model for those who follow after. A good example of this is the models of deconversion that appeared during the Romantic period. Barbour summarises the argument of M.H. Abrams (1971), who holds that Romantic writers were prone to reproduce a secularised form of older models of spiritual autobiography, wherein they construed their artistic calling as a transformation of their earlier religious commitments. In such autobiographies, the plot does not recount a separate level of events, rather the writer understands the plot as the deconversion itself. The pinnacle of human achievement in Romanticism is artistic creation, and hence the literary account of transformation accomplishes what it describes, the substitution of an artistic orientation for a religious one.

In his paper entitled "Belief, Deconversion, and Authenticity among U.S. Emerging Evangelicals," James Bielo (2012) illustrates the constitutive role of narrative in processes of religious change. Bielo presents something of a special case in discussing deconversion narratives among what he calls emerging evangelicals. A central notion among such groups is that traditional Christianity overemphasises belief-assent to certain canonical propositions - as the essence of the faith. In narratives that describe their abandoning of this position, these emerging evangelicals are in essence displaying their new faith by narrating it. That is, the key element of their new faith is precisely a denial of the importance of belief as traditionally understood, so the deconversion narrative cannot take shape around transition between beliefs. In light of this, the narrative assumes a special importance in articulating what it is that the believer has come to accept. There is no institution or proposition to which the deconversion can be tied, rather there is only the narrative to formulate the coherence of the new faith. In the case of one of Bielo's subjects, Glenn, this narrative concerns a particular sort of social relationship, "the collective 
experience of everyday life with his house church members." (Bielo 2012: 269). It is this story, and others like it, that constitutes faith.

\section{$4 \quad$ Critical Reflections, Evaluations and Predictions}

Streib and his colleagues, in the study discussed above, include a considerable amount of narrative material in their analysis, using long direct quotes from the interviews. However, in that they adopt a generally positivist orientation, this aspect of the work to some extent undermines the overall thrust of their analysis. The story of Gina, for example, is presented as a paradigmatic narrative of one of their four categories, pursuit of autonomy. Yet the narrative itself centers on the role of a romantic relationship in triggering Gina's exit from the Mormon faith. The man she loves loses his faith, and her inability to remain apart from him eventually leads her to also leave the church. This is, as the authors say, a process of separation from the religious community into which the subject was born, and hence fairly described as the pursuit of autonomy. But Gina's deconversion might just as accurately be described as driven by the effort to preserve a valued social relationship, which is quite different from a pursuit of autonomy.

The problem here is that the coding methods that are typical of the positivist orientation, by design, abstract from the rich details of a narrative account in order to identify simplified factors that characterise some social phenomenon. The more one moves in the direction of reporting narrative detail, the more one undermines one's efforts to extract a few general explanatory elements from the narratives.

More broadly, the positivist approach has two sorts of disadvantages. First, it is fair to say that these approaches to narratives ignore the bulk of the narratives they examine. The analyst strips away the vast majority of what the narrator actually says, on the grounds that it is not relevant to the basic categories the researcher has developed for his or her coding system. What is removed may contain much that is vital to the narrative. In addition to neglecting all parts of the narrative that are not captured by the coding system, this process removes many of the narrator's values, their sense of how different experiences fit together into a cohesive plot, the way they use symbolic resources to map the idiosyncrasies of their own biography and temperament, the rhetorical and other discursive resources the narrator uses, aspects of narrative performance such as voicing and timing, and so on.

The effect of all this is that in this approach one necessarily ignores the narrative conventions that structure stories of deconversion, and consequently 
the ways in which such conventions may condition understandings of self and history. This is the second disadvantage of the positivist approach: it ignores the possibility that narrative itself may play a role in the phenomenon of deconversion. That is, narrative is not only a research method, it is a cultural mechanism whereby persons make sense of their lives. For this reason, changing narratives may just as well constitute as describe the phenomenon of religious change. Barbour's and Bielo's close attention to full narratives of deconversion help to illustrate that the practice of reducing narratives to the assertion of various social and psychological factors not only misses much of the narratives, but much of deconversion. This is not to deny the value of positivist approaches, which I have used at times in my own work (Stromberg et al. 2007). Such approaches can allow us to gain a sense of the typical patterns in a corpus of interviews, and ultimately begin to develop an understanding of the sorts of social and psychological factors that are implicated in leaving religions. However, in that the topic of this chapter is narrative and autobiographical analysis, it must be noted that in the positivist approach narrative is typically used as an extended form of questionnaire research. One hopes, in the long term, for the development of mixed methods approaches that can combine the strength of both positivist and discursive orientations.

\section{Suggestions How to Do It}

In this final part I will briefly outline an expansion of the discursive approach that I believe may prove of considerable value in the study of narratives about religious change. In several recent publications (Stromberg 2018; Stromberg 2019), I have attempted to lay the foundation for a style of narrative analysis that builds on my earlier work (Stromberg 1993) by focusing on performative and discursive aspects of narratives. Very often narratives go beyond describing distant situations, rather they attempt to depict them. Especially where a speaker is concerned with something emotionally salient—such as a story about a change in her faith - she will, both intentionally and unintentionally, make that change present in the moment of telling. This means that her story will likely be rich in the numerous methods speakers use to depict: manual gestures, facial portrayals, direct quotation, analogies and metaphors, incorporation of other narratives, and so on (see Keane 2008)

Focusing on these discursive features allows us to understand narratives as tools used by speakers and hearers to build cultural environments. In narratives, participants build a world. The theoretical impetus for this conceptualisation cannot be fully presented here, but is rooted in contemporary attempts 
to understand the close relationship between cognition in general and the environment. Anthropologist Tim Ingold (2000), for example, points out that the mind "is immanent in the network of sensory pathways that are set up by virtue of the perceiver's immersion in his or her environment." (Ingold 2000:3)

Rather than approaching thinking as a process carried out exclusively in a brain separated from the world, we should study the ways that thinking is embedded in the world. Such attempts are prefigured in the American pragmatist tradition. Shaun Gallagher (2014: 115-116) summarises John Dewey's view of cognition as follows: "For Dewey's understanding of cognition, the unit of explanation is not the biological individual, the body by itself, or the brain, but the organism-environment...Dewey was influenced by Peirce's view that in coping with a problematic situation, we use physical tools as well as ideas to physically reshape the environment. This includes linguistic tools, which in communicative contexts may be used to reshape the dynamics of the situation." To see narratives in this way is to open up new possibilities for understanding such matters as - to take the matter before us here-how believers use stories to conceptualise and re-conceptualise their situations.

An example, taken from a different realm of discourse, provides a small but powerful example. In a recent paper (Stromberg 2018), I discussed a psychotherapy patient-pseudonym Darby — with whom I worked with many years ago. I want to focus on one brief moment in our final session together. Darby was relating a dream about a long lost boyfriend. As we talked about the dream, it emerged that its setting was much like the office in which we were sitting. I pointed out that the long-lost boyfriend could also be me, and Darby said, "but I wouldn't take you to a place like that." When I asked where she would take me, she said "out to lunch." My point here is the way that response served to transform the situation created by the narrative. It suggests a completely new reading of the dream narrative, which is associated with a transformed relationship between Darby and myself, and hence a transformed moral context. The fact that this new relationship and moral context would have been completely inappropriate serves to underline how this small change in the narrative utterly transformed the environment in which Darby and I were operating.

The way that even minor changes can change an environment, including such matters as the underlying moral basis of the situation, illustrates the point I want to emphasise here. From this perspective, leaving a religion can be conceptualised as leaving the institutional, cultural, and communal territory of the religion. Of course, one can only move by going somewhere else, and hence leaving will inevitably entail taking up a new set of images and ideas and beliefs. What we should be looking for in narrative approaches, then, is why 
and how old symbolic environments are traded for new ones, and the ongoing implications of this change.

As I have emphasised, such understanding can only grow out of detailed and careful attention to full narratives and their performance. While the sort of analysis that I labelled positivist above has its place, it cannot fairly be labelled the study of narrative. Instead, it uses narrative as a research method to extend and supplement a reductive approach to the matter of deconversion. This may sound like a criticism, but I do not intend it as such. This sort of work has an important role to play in the investigation of leaving religion, however it is not to be confused with narrative analysis.

The analyst should treat a deconversion narrative or autobiography as the present instantiation of the social process of leaving religion. Even if that leaving occurred decades ago, its traces upon history and the person exist only as they are formulated in the present, only as they constitute the current environment of the narrator. Careful attention to the myriad linguistic and paralinguistic features of the narrative and —if possible-its performance, will be rewarded by subtle insights into how the narrative creates a cognitive environment appropriate to a particular form of faith. Such information will provide new avenues for understanding why people leave religions, and what happens as a result.

\section{References}

Abrams, M.H. 1971. Natural Supernaturalism: Tradition and Revolution in Romantic Literature. New York: W.W. Norton.

Avance, R. 2013. "Seeing the Light: Mormon Conversion and Deconversion Narratives in Off- and Online Worlds." Journal of Media and Religion. 12:1, 16-24.

Bielo, J. 2012. "Belief, Deconversion, and Authenticity among U.S. Emerging Evangelicals." Ethos. 40:3, 258-276.

Barbour, JD. 1994. Versions of Deconversion. Autobiography and the Loss of Faith. Charlottesville: University of Virginia Press.

Bromley, D.G. 1988. Falling From the Faith. Causes and Consequences of Religious Apostasy. Beverly Hills: Sage Publishers.

Enstedt, D., and Larsson, G. 2013. "Telling the Truth about Islam? Apostasy Narratives and Representations of Islam on WikiIslam.net." Cyberorient, Online Journal of the Virtual Middle East. At http://www.cyberorient.net/article.do?articleId=8459. Accessed 09/10/2017.

Fowler, J.W. 1991 [1979]. Stages of Faith. The Psychology of Human Development and the Quest for Meaning. San Francisco: HarperCollins. 
Gallagher, S. 2014. "Pragmatic Interventions into Enactive and Extended Conceptions of Cognition.” Philosophical Issues. 24:1, 110-126.

Gooren, H. 2010. Religious Conversion and Disaffiliation. Tracing Patterns of Change in Faith Practices. New York: Palgrave MacMillan.

Gooren, H. 2011. "Deconversion: Qualitative and Quantitative Results from CrossCultural Research in Germany and the United States: A Review Essay." Pastoral Psychology. 6o:4, 6o9-617.

Ingold, T. 2000. The Perception of the Environment. Essays on livelihood, dwelling and Skill. London and New York: Routledge.

Jacobs, J. 1987. "Deconversion from Religious Movements: An Analysis of Charismatic Bonding and Spiritual Commitment." Journal for the Scientific Study of Religion. 26:3, 294-308.

Keane, W. 2008. "The evidence of the senses and the materiality of religion." Journal of the Royal Anthropological Institute. 14:S1, S110-S127.

Larsson, G. 2017. "Apostasy and counter-narratives - two sides of the same coin: The example of the Islamic State." The Review of Faith and International Affairs. 15:2, 45-54.

Rothbaum, S. 1988. "Between Two Worlds: Issues of Separation and Identity After Leaving a Religious Community." In D.G. Bromley, ed., Falling From the Faith: Causes and Consequences of Religious Apostasy. London: Sage Publications, 205-228.

Streib, H., Hood Jr. R.W., Keller, B., Csoff, R-M., and Silver, C.F. 20og. Deconversion. Qualitative and Quantitative Results from Cross-Cultural Research in Germany and the United States of America. Gottingen, Germany: Vandenhoeck and Ruprecht.

Stromberg, P. 1993. Language and Self-Transformation. Cambridge: Cambridge University Press.

Stromberg, P. 2018. "Narrative and Healing in Dynamic Psychotherapy: Implications for Culture Theory." In N. Quinn, ed., Advances in Culture Theory from Psychological Anthropology. New York: Palgrave, 247-284.

Stromberg, P. 2019. "Narrative Analysis." In S. Coleman and J. Robbins, eds., The Oxford Handbook of the Anthropology of Religion. Oxford: Oxford University Press. (Under Review).

Stromberg, P., Nichter, M., and Nichter, M. 2007. "Taking Play Seriously: Low level smoking among college students." Culture, Medicine and Psychiatry. 31:1, 1-24.

Wright, B.R.E., Giovanelli, D, Dolan, E.G., and Edwards, M.E. 2011. "Explaining Deconversion from Christianity. A Study of Online Narratives." Journal of Religion and Society. 13:2, 1-17. 